\title{
Prebiotics and resistance to gastrointestinal infections
}

\author{
G. R. Gibson*, A. L. McCartney and R. A. Rastall \\ Food Microbial Sciences Unit, School of Food Biosciences, The University of Reading, P. O. Box 226, \\ Whiteknights, Reading RG6 6AP, UK
}

\begin{abstract}
Acute gut disorder is a cause for significant medicinal and economic concern. Certain individual pathogens of the gut, often transmitted in food or water, have the ability to cause severe discomfort. There is a need to manage such conditions more effectively. The route of reducing the risk of intestinal infections through diet remains largely unexplored. Antibiotics are effective at inhibiting pathogens; however, these should not be prescribed in the absence of disease and therefore cannot be used prophylactically. Moreover, their indiscriminate use has reduced effectiveness. Evidence has accumulated to suggest that some of the health-promoting bacteria in the gut (probiotics) can elicit a multiplicity of inhibitory effects against pathogens. Hence, an increase in their numbers should prove effective at repressing pathogen colonisation if/when infectious agents enter the gut. As such, fortification of indigenous bifidobacteria/lactobacilli by using prebiotics should improve protection. There are a number of potential mechanisms for lactic acid bacteria to reduce intestinal infections. Firstly, metabolic endproducts such as acids excreted by these micro-organisms may lower the gut pH to levels below those at which pathogens are able to effectively compete. Also, many lactobacilli and bifidobacteria species are able to excrete natural antibiotics, which can have a broad spectrum of activity. Other mechanisms include an improved immune stimulation, competition for nutrients and blocking of pathogen adhesion sites in the gut. Many intestinal pathogens like type 1 fimbriated Escherichia coli, salmonellae and campylobacters utilise oligosaccharide receptor sites in the gut. Once established, they can then cause gastroenteritis through invasive and/or toxin forming properties. One extrapolation of the prebiotic concept is to simulate such receptor sites in the gut lumen. Hence, the pathogen is 'decoyed' into not binding at the host mucosal interface. The combined effects of prebiotics upon the lactic acid flora and anti-adhesive strategies may lead towards new dietary interventions against food safety agents.
\end{abstract}

Gut pathogens: Prebiotics: Bifidobacteria: Inulin

\section{The problem of gastroenteritis}

While viruses probably cause the most cases of gastroenteritis in children and adults, bacteria are the most problematic in terms of food safety. Eating foods containing pathogenic micro-organisms or their toxins may cause so-called 'food poisoning'. Clinical features of gastroenteritis vary greatly and may range from mild to life-threatening. Symptoms include vomiting, nausea, abdominal cramps and/or diarrhoea, depending on the causative agents. A microbiological detection is usually carried out to confirm the diagnosis. Bacteria form a principal concern because they are very ubiquitous and are therefore likely to contaminate food in the first place. Moreover, the food environment can provide a good matrix and substrate supply for growth. Bacteria proliferate at a quick rate, although the minimum level for detection does vary markedly. Common sources of bacterial food contamination are shown in Table 1.

Many bacteria capable of causing food poisoning reside within the gut flora of humans and animals. As such, there is a risk of infection in meat and poultry, particularly at the time of slaughter. However, it is important to realise that poor slaughter practices may lead to infection, even in the cleanest of slaughterhouses. Similarly, contamination of dairy produce may occur through the use of non-pasteurised milk, while vegetables may be exposed to risk if animal manure is used as the fertiliser.

While infection through the food chain to the human gut is possible by various means, it is clear that steps are being taken to avoid the risk. Bacterial growth in foods can be affected by temperature, acidity and moisture content. In the kitchen this is readily controlled by adequate cooking of the food, with temperatures of around $100^{\circ} \mathrm{C}$ being lethal for vegetative bacterial cells. However, some bacteria (e.g. clostridia, bacilli) are able to produce spores that are more resistant to this. Thus, it is imperative that the cooking process is thorough, with correct handling and storage also adding significantly towards the hygienic process.

Microbiological food safety currently has a major consumer, industrial and research profile. Nevertheless, food for human consumption has never been so safe as is the current case. However, the incidence of food poisoning seems to increase on an annual

Table 1. Examples of principal bacterial causes of food poisoning

\begin{tabular}{ll}
\hline Bacterial species & $\begin{array}{l}\text { Common foods that } \\
\text { may be contaminated }\end{array}$ \\
\hline Bacillus cereus & Cooked rice, meat \\
Campylobacter spp. & Poultry, unpasteurised milk \\
Clostridium botulinum & Fish, meat \\
Clostridium perfringens & Cooked meat, poultry \\
Escherichia coli & Meat, raw milk \\
Listeria monocytogenes & Pâté, soft cheeses \\
Salmonellae & Meat, poultry, eggs \\
Shigella spp. & Eggs, salads \\
Staphylococcus aureus & Ham, poultry, dairy products \\
Yersinia enterocolitica & Milk, poultry \\
\hline
\end{tabular}


basis. Undoubtedly, this is closely related to better methods of detection and prediction, including the use of genetic-based methodologies that have high reliability and sensitivity. The economic costs and medical aspects of acute gastroenteritis are huge, e.g. time lost from employment, clinical costs and patient suffering.

Pathogens may either colonise and grow within the gastrointestinal tract and then invade host tissue, or they may secrete toxins contaminating food prior to its ingestion. Such toxins disrupt the function of the intestinal mucosa, causing nausea, vomiting and diarrhoea. The principal human intestinal bacterial pathogens can be characterised according to the virulence factors that enable them to overcome host defences. These include invasion that enables bacterial multiplication within enterocytes or colonocytes, for example Escherichia coli, Shigella spp., salmonellae and yersinae. Cytotoxic bacteria, which include the enteropathogenic and enterohaemorrhagic strains of $E$. coli as well as some shigellae, are able to produce substances that directly cause cell injury. Toxigenic bacteria, such as Vibrio cholerae, and some shigellae are capable of producing enterotoxins, which affect salt and water secretion in the host. Lastly, enteroaggregative E. coli have the ability to tightly adhere to the colonic mucosa. Such mechanisms enable potentially pathogenic bacteria to establish infections in the gastrointestinal tract, evade the immune system and surmount colonisation resistance afforded by the indigenous gut microflora.

Acute gastroenteritis probably affects most people at one time or other during their lives. In particular, the consequences can be devastating in more susceptible persons, e.g. young children and the elderly. Persons who are frequent travellers or exposed to antibiotics are especially susceptible. Every effort is made to eradicate pathogens from the food chain. However, given the variability involved this is almost impossible to achieve. Hence, attention has turned to the gut microbial ecosystem as an effective 'barrier' to pathogens, i.e. fortification of the microflora such that improved colonisation resistance occurs.

\section{Role of the gut flora in colonisation resistance}

The gut microflora and the mucosa themselves may act as barriers against invasion by potential pathogens. Bifidobacteria and lactobacilli can inhibit pathogens like E. coli, Campylobacter and Salmonella spp. (Gibson \& Wang, 1994a). The lactic microflora of the human gastrointestinal tract is thought to play a significant role in the improved colonisation resistance (Gibson et al. 1997). A number of plausible mechanisms are in operation:

- metabolic endproducts, such as acids, excreted by these micro-organisms may lower the gut $\mathrm{pH}$, in a microniche, to levels below those at which pathogens are able to effectively compete;

- competitive effects from occupation of normal colonisation sites;

- direct antagonism through natural antimicrobial excretion (lactic acid bacteria produce inhibitory peptides);

- competition for nutrients which may be limiting; and

- enhancement of the immune system.

The outbreak of E. coli $\mathrm{O} 157$ in Lanarkshire, Scotland, at the end of 1996, resulted in twenty-one fatalities and was one of the world's most serious food poisoning incidents ever. The deaths have highlighted the continuing concern of bacterial gastroenteritis to consumers, the food industry, researchers and the medical profession. In laboratory tests we have also shown that some bifidobacteria exert powerful antagonistic effects towards $E$. coli O157. The inhibition was variable in species of bifidobacteria, with Bifidobacterium infantis and Bifidobacterium longum exerting the greatest effect on $E$. coli. The possibility exists, therefore, that increased levels of bifidobacteria (and consideration of the species type) in the large gut may, along with other factors such as immune status, offer improved protection. Above the age of about 55 years, faecal bifidobacteria counts are known to show a marked decrease in comparison to those of younger persons (Mitsuoka, 1990). It may be of some relevance that the UK fatalities, during the E. coli outbreak, all involved the elderly, while hundreds of people in different age groups reported the infection. A potential correlation exists with reduced pathogen resistance, decreased numbers of bifidobacteria in the elderly and the production of natural resistance factors. In essence, the natural gut flora may have been compromised through reduced bifidobacteria numbers and may have a diminished ability to deal with pathogens. If prebiotics are used to increase bifidobacteria or lactobacilli towards being the numerically predominant genus in the colon, an improved colonisation resistance will result.

\section{The use of prebiotics}

Inulin is a polysaccharide of the form Glu $\alpha 1-2[\beta \text { Fru 1-2 }]_{n}$, where $n>10$ (Crittenden \& Playne, 1996). The structural relatives of inulin, i.e. inulin-type fructans, are the best-documented oligosaccharides for their effect on intestinal bifidobacteria and are considered important prebiotic substrates. They are produced in large quantities in several countries and can be added to various products such as biscuits, drinks, yoghurts, breakfast cereals, spreads, dairy products, beverages, infant foods, bakery products, animal feeds, pet foods and sweeteners (Mizota, 1996). Inulin also occurs naturally in Western foods, such as onion, asparagus, leek, garlic, wheat and artichoke, although to a lesser extent than in chicory (Gibson et al. 1994).

Batch culture studies where faecal slurries were incubated with inulin, oligofructose (OF), starch, polydextrose, fructose and pectin for $12 \mathrm{~h}$ (Wang \& Gibson, 1993) showed the greatest increase in bifidobacteria with $\mathrm{OF}$ and inulin, indicating the prebiotic nature of these substrates. Continuous culture systems inoculated with faecal slurries were later used to investigate fermentation of inulin-type fructans (Gibson \& Wang, 1994a,b). In accordance with earlier studies, bifidobacteria, and to a lesser extent lactobacilli, preferred $\mathrm{OF}$ and inulin to glucose, whereas bacteroides could not grow on OF. By varying parameters in the chemostat, optimum conditions for growth of bifidobacteria, but inhibition of bacteroides, clostridia and coliforms, were concluded to be low $\mathrm{pH}(\mathrm{pH} 5 \cdot 5)$, high culture dilution rate $(0 \cdot 3 / \mathrm{h})$ and $1 \%(\mathrm{w} / \mathrm{v})$ concentration of carbohydrate, i.e. similar to the physico-chemical environment of the proximal colon. Three-stage chemostats confirmed the enhanced proliferation of bifidobacteria by OF in conditions resembling the proximal colon (Gibson \& Wang, 1994a; McBain \& Macfarlane, 1997).

A later single-stage chemostat study, with inulin-type fructans (Sghir et al. 1998), demonstrated discrepancies between classical microbiological techniques and molecular approaches. Agar plate counts showed an increase in the combined populations of bifidobacteria and lactobacilli that reached $98.7 \%$ of the total bacterial flora by steady state. However, 16S rRNA genus-specific probes indicated an initial increase in the bifidobacteria population that decreased after $6 \mathrm{~d}$, while lactobacilli thrived in the low $\mathrm{pH}$ 
fermenter ( $\mathrm{pH} 5 \cdot 2-5.4)$ maintaining a high population at steady state. The changes observed in the SCFA profile corresponded well with the population data obtained through probe methods.

Rats that were previously fed tyrosine and tryptophan (capable of producing putrefactive products) were administered a $10 \%$ (w/v) fructan diet, and this resulted in increased SCFA, decreased faecal $\mathrm{pH}$, and significantly decreased concentrations of the tyrosine derivatives phenol and $p$-cresol (Hidaka et al. 1986).

Several studies have been conducted using human subjects, although the dose, substrate, duration and volunteers vary. A general observation was the greater bifidogenic effect of substrates in subjects with a low initial bifidobacteria count $\left(10^{7} / \mathrm{g}\right.$ faeces $)$ than in those with high initial numbers $\left(10^{9.5} / \mathrm{g}\right.$ faeces; Hidaka et al. 1986). Also, a negative correlation between bifidobacteria and Clostridium perfringens was observed suggesting that the former may inhibit growth of the latter in the intestine, supporting earlier studies (Wang \& Gibson, 1993; Gibson \& Wang, 1994c). There were large variations between the subjects in their microflora compositions and response to the substrates (Hidaka et al. 1986; Williams et al. 1994; Buddington et al. 1996), particularly between Western and Eastern subjects (Buddington et al. 1996). Another general observation was the decrease in bifidobacteria once administration of the prebiotic ceased (Bouhnik et al. 1994; Buddington et al. 1996). Human trials with oligofructose and inulin have consistently demonstrated an efficient prebiotic effect, most markedly a stimulation of bifidobacteria (Gibson et al. 1995; Buddington et al. 1996; Kleesen et al. 1997; Tuohy et al. 2001).

Thus, an efficient prebiotic, like inulin, can stimulate changes in the gut flora that make the host more resistant to agents that cause gastroenteritis. Studies on this are currently few (Table 2), but given the ease of use and multiple mechanisms involved, there is much potential. One important study (Cummings et al. 2001) showed the positive effect of inulin on the incidence of diarrhoea in travellers.

\section{Enhancing functionality}

The idea of combining prebiotic properties with anti-adhesive activities is currently under investigation. This would add major functionality to the approach of altering gut pathogenesis. Many intestinal pathogens utilise monosaccharides or short oligosacchar-

Table 2. Examples of studies showing that prebiotics may reduce acute pathogenesis of the gut

\begin{tabular}{|c|c|}
\hline $\begin{array}{l}\text { Oligofructrose and inulin protected against } \\
\text { Listeria monocytogenes and Salmonella } \\
\text { typhimurium as well as chemically } \\
\text { induced tumours }\end{array}$ & Buddington et al. (2002) \\
\hline $\begin{array}{l}\text { Reduced incidence of traveller's } \\
\text { diarrhoea with inulin }\end{array}$ & Cummings et al. (2001) \\
\hline $\begin{array}{l}\text { Inulin affects immunology through } \\
\text { macrophage activation and through } \\
\text { cell wall fragments of bifidobacteria }\end{array}$ & Meyer et al. (2000) \\
\hline $\begin{array}{l}\text { Inulin in an oral electrolyte solution } \\
\text { accelerated beneficial bacteria and } \\
\text { recovery from diarrhoea }\end{array}$ & Oli et al. (1998) \\
\hline $\begin{array}{l}\text { Prebiotic fermentation increased } \\
\text { organic acids, which may be useful } \\
\text { for suppressing pathogens }\end{array}$ & Kleessen et al. (1997) \\
\hline $\begin{array}{l}\text { Bifidobacterium breve plus } \\
\text { transgalactosylated oligosaccharides } \\
\text { inhibited Salmonella enteritica }\end{array}$ & Asahara et al. (2001) \\
\hline
\end{tabular}

ide sequences as receptors and knowledge of these receptor sites has relevance for biologically enhanced prebiotics (Table 3). Binding of pathogens to these receptors is the first step in the colonisation process (Finlay \& Falkow, 1989; Karlsson, 1989). There are currently several pharmaceutical preparations based upon such oligosaccharides in clinical trials. These agents are multivalent derivatives of the sugars and act as 'blocking factors', dislodging the adherent pathogen (Heerze et al. 1994; Jayaraman et al. 1997). There is potential for developing prebiotics which incorporate such a receptor monosaccharide or oligosaccharide sequence. These molecules should have enough anti-adhesive activity to inhibit binding of low levels of pathogens. They can therefore be thought of as 'decoy oligosaccharides'.

Our studies (Brück et al. 2003) have shown that prebiotics with anti-adhesive capabilities could reduce the symptoms of enteropathogenic E. coli (EPEC) challenge in a monkey model. Glycomacropeptide (GMP) has the potential to mimic glycans that bacteria use for attachment, thereby inhibiting pathogen colonisation. $\alpha$-Lactalbumin (ALA) aids in the production of lactose, which, upon fermentation, produces an environment inhospitable to pathogens. Infant macaques were breast- or formula-fed with ALA or GMP from birth to 5 months of age. At 4.5 months, $10^{8} \mathrm{cfu}$ of EPEC was given. Gut microflora (rectal swabs) were quantified by fluorescent in situ probing and the response to an infection assessed. At 4.5 months, $10^{8} \mathrm{cfu}$ of EPEC was given. Breast-fed primates experience no diarrhoea, as did those supplemented with ALA. Formula-fed groups had acute effects and those fed with GMP only experienced intermittent diarrhoea. These results show that supplemented formula could aid development of a more host-friendly flora and may improve the ability to resist acute infection in a model system very close to man.

The prebiotic concept may be extrapolated further by considering an attenuation of virulence in certain food-borne pathogens. For example, the plant-derived carbohydrate cellobiose is able to repress the pathogenicity of Listeria monocytogenes through down-regulation of its virulence factors (Park \& Kroll, 1993). As such, this organism is avirulent in its natural habitat of soil, where it is exposed to rotting vegetation and therefore cellobiose. In the human body, an absence of cellobiose may allow the virulence factors to be expressed, and it is possible that further incorporation of this disaccharide to foods susceptible to Listeria contamination could reduce this virulence.

\section{Conclusions}

Given the burden and risk of microbial-associated gastroenteritis, the route of using prebiotics to fortify the gut flora and improve colonisation resistance holds much potential. Prebiotics like inulin-type fructans have powerful stimulatory effects upon the

Table 3. Receptor saccharides for gastrointestinal pathogens and toxins

\begin{tabular}{|c|c|}
\hline Gal $\alpha 4 \mathrm{Gal}$ & Escherichia coli (P-piliated), Vero cytotoxin \\
\hline Galß4GlcNAcß3Gal & Streptococcus pneumoniae \\
\hline GalNAc $\beta 4 G a l$ & $\begin{array}{l}\text { Pseudomonas aeruginosa, Haemophilus influenzae } \\
\text { Staphylococcus aureus, Klebsiella pneumoniae }\end{array}$ \\
\hline Sialic acids & E. coli (S-fimbriated) \\
\hline Gal $\alpha 3 G a l \beta 4 G \mid c N A c$ & Clostridium difficile toxin $\mathrm{A}$ \\
\hline Fucose & Vibrio cholerae \\
\hline GlcNAc & E. coli, V. cholerae \\
\hline Mannose & $\begin{array}{l}\text { E. coli, Klebsiella aerogenes, Salmonella spp. } \\
\text { (type } 1 \text { fimbriated) }\end{array}$ \\
\hline
\end{tabular}


bifidobacteria that, in turn, exert several anti-pathogenic mechanisms. Future challenges may include an extrapolation of the prebiotic concept into anti-adhesive aspects.

\section{References}

Asahara T, Nomoto K, Shimizu K, Watanuki M \& Tanaka R (2001) Increased resistance of mice to Salmonella enteritica serovar Typhymurium infection by synbiotic administration of bifidobacteria and transgalactosylated-oligosaccharides. J Appl Microbiol 91, 985-996.

Bouhnik Y, Flourie B, Ouarne F, Riottot M, Bisetti N, Bornet F \& Rambaud JC (1994) Effects of prolonged ingestion of fructo-oligosaccharides (FOS) on colonic bifidobacteria, fecal enzymes and bile acids in humans. Gastroenterology 106, A598.

Brück WB, Kelleher S, Gibson GR, Nielsen KE, Chatterton DEW \& Lönnerdal B (2003) rRNA probes used to quantify the effects of glycomacropeptide and $\alpha$-lactalbumin supplementation on the predominant groups of intestinal microflora of infant rhesus monkeys challenged with enteropathogenic Escherichia coli. J Pediatr Gastroenterol Nutr 37, 273-280

Buddington RK, Williams CH, Chen S \& Witherly SA (1996) Dietary supplement of neosugar alters the fecal flora and decreases activities of some reductive enzymes in human subjects. Am J Clin Nutr 63, $709-716$.

Buddington KK, Danohoo JB \& Buddington RK (2002) Dietary oligofructose and inulin protect mice from enteric and systemic pathogens and tumour inducers. J Nutr 132, 472-477.

Crittenden RG \& Playne MJ (1996) Production, properties and applications of food-grade oligosaccharides. Trends Food Sci Technol 7, $353-361$.

Cummings JH, Christie S \& Cole TJ (2001) A study of fructooligosaccharides in the prevention of travellers' diarrhoea. Aliment Pharmacol Ther 15, 1139-1145.

Finlay BB \& Falkow S (1989) Common themes in microbial pathogenicity. Microbiol Rev 53, 210-230.

Gibson GR \& Wang X (1994a) Enrichment of bifidobacteria from human gut contents by oligofructose using continuous culture. FEMS Microbiol Lett 118, 121-128.

Gibson GR \& Wang X (1994b) Regulatory effects of bifidobacteria on the growth of other colonic bacteria. J Appl Bacteriol 77, 412-420.

Gibson GR \& Wang X (1994c) Bifidogenic properties of different types of fructo-oligosaccharides. Food Microbiol 11, 491-498.

Gibson GR, Willis CL \& Van Loo J (1994) Non-digestible oligosaccharides and bifidobacteria - implications for health. Int Sugar J 96, 381-387.

Gibson GR, Beatty ER, Wang X \& Cummings JH (1995) Selective stimulation of bifidobacteria in the human colon by oligofructose and inulin. Gastroenterology 108, 975-982.
Gibson GR, Saavedra JM, Macfarlane S \& Macfarlane GT (1997) Gastrointestinal microbial disease. In Probiotics 2: Application and Practical Aspects, pp. 10-39 [R Fuller, editor]. Andover: Chapman and Hall.

Heerze LD, Kelm MA \& Talbot JA (1994) Oligosaccharide sequences attached to an inert support (SYNSORB) as potential therapy for antibiotic-associated diarrhoea and pseudomembranous colitis. J Infect Dis 169, 1291-1296.

Hidaka H, Eida T, Takizawa T, Tokunaga T \& Tashiro Y (1986) Effects of fructooligosaccharides on intestinal flora and human health. Bifidobacteria Microflora 5, 37-50.

Jayaraman N, Nepogodiev SA \& Stoddart JF (1997) Synthetic carbohydrate-containing dendimers. Chem Eur J 3, 1193-1199.

Karlsson KA (1989) Animal glycosphingolipids as membrane attachment sites for bacteria. Annu Rev Biochem 58, 309-350.

Kleessen B, Sykura B, Zunft H-J \& Blaut M (1997) Effects of inulin and lactose on fecal microflora, microbial activity and bowel habit in elderly constipated persons. Am J Clin Nutr 65, 1397-1402.

McBain AJ \& Macfarlane GT (1997) Investigations of bifidobacterial ecology and oligosaccharide metabolism in a three-stage compound continuous culture system. Scand J Gastoenterol 32, 32-40.

Meyer DP, Tungland BC, Causey JL \& Slavin JL (2000) The immune effects of inulin in vitro and in vivo. Agro-Food Ind Hi Technol 11, $18-20$.

Mitsuoka T (1990) Bifidobacteria and their role in human health. $J$ Ind Microbiol 6, 263-268.

Mizota T (1996) Functional and nutritional foods containing bifidogenic factors. Bull Int Dairy Found 313, 31-35.

Oli MW, Petschow BW \& Buddington RK (1998) Evaluation of fructooligosaccharide supplementation of oral electrolyte solutions for treatment of diarrhea. Recovery of the intestinal bacteria. Dig Dis Sci 43, $138-147$.

Park SF \& Kroll RG (1993) Expression of listeriolysin and phosphatidylinositol-specific phospholipase $\mathrm{C}$ is repressed by the plant-derived molecule cellobiose in Listeria monocytogenes. Mol Microbiol 8, 653-661.

Sghir A, Chow JM \& Mackie RI (1998) Continuous culture selection of bifidobacteria and lactobacilli from human faecal samples using fructooligosaccharide as selective substrate. J Appl Microbiol 85, 769-777.

Tuohy KM, Finlay RK, Wynne AG \& Gibson GR (2001) A human volunteer study on the prebiotic effects of HP-Inulin - gut bacteria enumerated using fluorescent in situ hybridisation (FISH). Anaerobe 7, $113-118$.

Wang X \& Gibson GR (1993) Effects of the in vitro fermentation of oligofructose and inulin by bacteria growing in the human large intestine. J Appl Bacteriol 75, 373-380.

Williams CH, Witherly SA \& Buddington RK (1994) Influence of dietary neosugar on selected bacterial groups of the human faecal microbiota. Microb Ecol Health Dis 7, 91-97. 